\title{
HR COMPETENCIES AT A MERged Higher EduCATION INSTITUTION
}

Author:

Cecile M. Schultz

\section{Affiliation:}

${ }^{1}$ Department People

Management and

Development, Tshwane

University of Technology,

South Africa

\section{Correspondence to:}

Cecile Schultz

email:

schultzcm@tut.ac.za

\section{Postal address:}

PO Box 19138, Pretoria

West, 0117

\section{Keywords:}

change; business

knowledge; HR

practices; personal skills;

management skills

\section{Dates:}

Received: 03 June 2009

Accepted: 24 Mar. 2010

Published: 15 June 2010

How to cite this article:

Schultz, C.M. (2010).

HR competencies at a merged Higher Education

Institution. SA Journal

of Human Resource

Management/SA Tydskrif vir

Menslikehulpbronbestuur,

8(1), Art. \#225, 8 pages. DOI:

10.4102/sajhrm.v8i1.225

\section{This article is available}

at:

http://www.sajhrm.co.za

(C) 2010. The Authors.

Licensee: OpenJournals

Publishing. This work

is licensed under the

Creative Commons

Attribution License.

\section{ABSTRACT}

Orientation: Certain human resource (HR) competencies are essential to assist with the dynamics of change in the higher education landscape.

Research purposes: The aim of this study was to determine the HR competencies at a merged higher education institution. Other objectives were to establish the satisfaction of academics, administrative staff and management regarding the HR competencies and the importance thereof.

Motivation for the study: Human resource professionals require assistance by providing HR competencies necessary to add value at a merged higher education institution.

Research designs, approaches and methods: A quantitative research design was employed as the research strategy. The questionnaire was based on the literature, the business plan and the HR balanced scorecard report. The target population was 1363 permanent staff on one campus and the response rate was $28 \%$. A principal factor analysis, spider charts and box plots were utilised for data analysis. The results indicated business knowledge, HR practices, personal skills and management skills as the vital HR competencies.

Practical implications: Staff were not satisfied with the current HR competencies and consequently this necessitated attention to improve the deficient areas.

Contribution: This study shows that limited research was done with regard to HR competencies in the South African higher education backdrop.

\section{INTRODUCTION}

The South African higher education system experienced a complex restructuring process of merging higher education institutions. Higher education institutions should treasure and nurture their own human capital during times of change (De Lange \& Olivier, 2008). Challenges like anxiety, low morale, work errors and loss of motivation can be caused by restructuring (Arnolds, 2005). Human resource (HR) departments have a role to play in dealing with these challenges. They could assist with creating an atmosphere of open communication that is free of fear, where loyalty is part of the organisation's success (Rampersad, 2003). The true competencies of HR, therefore, are those that add value and help predict success (Nel, Van Dyk, Haasbroek, Schultz, Sono \& Werner, 2006). The HR function could fulfil a more central role in merged institutions and should make a contribution to the success of higher education institutions. This needs to be done by creating a HR capability that ensures that institutions remain responsive to their environments and maintain their competitive edge. Brewster, Carey, Grobler, Holland and Warnich (2008) urge that HR competencies need to be identified and developed to increase the competitive advantage.

It is against this background that the HR department should have a HR strategy that is aligned to the organisation's business strategy in order to gain a competitive advantage over its rivals. Birkin (2005) raises the question about whether the HR management has demonstrable evidence of adding value and asks how it is assessed. Measurement systems should be carefully matched with the institution's unique competitive strategy and operational goals (Becker, Huselid \& Ulrich, 2001). Measurement is critical to the achievement of strategy and adding value. According to Hayes (2008, p. 1), 'You can't manage what you can't measure.'

The balanced scorecard approach to performance measurement was introduced as a method of evaluating organisational performance from various perspectives. It is a performance measurement tool that takes into account four areas - financial, customers, internal processes and people/ innovation/growth assets - that contribute to an institution's performance (Kaplan \& Norton, 2001). According to this approach, managers should develop goals in each of these areas and then measure whether the goals are being met in order to ensure the adding of value to the company. The necessary essential HR competencies can then be established. In this article, the related concepts of value, HR competencies and the HR balanced scorecard will be discussed. Against this background, the study reported in the article aimed to determine the essential HR competencies required to add value within the context of the challenges posed at a merged higher education institution.

It is imperative to determine the value of the various HR functions as they impact on adding value to the organisation. Value reflects the standards within an institution. George and Jones (2007, p. 567) define value as 'general criteria, standards or guiding principles that people use to determine which type of behaviors, events, situations, and outcomes are desirable or undesirable.'

HR needs a measurement system that focuses on value creation. Ulrich (1997) elaborates on value creation by stating that it is a process that deals with the way in which value can be added for the user of a service rather than paying attention to a function. Presently, HR management involves becoming a business partner and plays a significant part in developing business strategy (Van der Westhuizen, Van Vuuren \& Visser, 2003). Zulu and Parumasur (2009) recommend that ongoing 
health surveys and the regular review of HR policies will disclose significant information to add value any organisation. Training gaps should be identified (Pillay \& Wijnbeek, 2006) as well as the implementation of strategies to retain staff (Martin \& Roodt, 2009). Van Vuuren and Eiselen (2006:27) state that 'HR tertiary education and professional training need to include business ethics knowledge and an ethics management competence'. Van Aswegen and Engelbrecht (2009) elaborate on this by stating that high standards of ethical behaviour and integrity encourage confidence and trust. Training in change management skills will improve the transformation process (Kilfoil \& Groenewald, 2005). The focus should shift to continual learning to gain the required skills to improve the transformation process (Smith \& Schurink, 2005). Obtaining these skills and starting to transform the HR department should add value to an organisation.

A template for the transformation of any staff function is helpful in the workplace. Ulrich and Brockbank (2005) suggest five elements that can be used to create such a template for transformation:

- Knowing external business realties (technology, economics, globalisation and demographics).

- Serving external and internal stakeholders (customers, investors, managers and employees).

- Crafting HR practices (people, performance, information and work).

- $\quad$ Building HR (HR organisation and strategy).

- Assuring HR professionalism (HR roles and competencies).

De Bruyn and Roodt (2009, p. 10) state that 'now, more than ever, business success comes for HR, and the 'DNA' for HR's success is the HR value proposition'. Transformation requires integrating the various HR practices and focusing them jointly on valuedadded elements such as intangibles, customer connection, organisation capabilities and individual abilities (Ulrich \& Brockbank, 2005). Dreher and Dougherty (2001) concur with Ulrich and Brockbank (Ulrich \& Brockbank, 2005) by stating that $\mathrm{HR}$ practices should be valuable and non-substitutable.

The HR department should consider different perspectives to contribute to this positive effect. Higgins (2007) contends that HR value (or contribution) can be viewed and ultimately measured from three different perspectives - namely, the value of the HR function to the institution as a whole, the value of HR processes and the quantification of people value to the organisation and their inputs into strategic decision-making.

These perspectives will determine the focus of the HR department. 'HR should not be defined by what it does but by what it delivers - results that enrich the organisation's value to customers, investors and employees' (Ulrich 1998, p. 29). The HR department also has a responsibility towards management. Meisinger (2003) suggests that HR resource-managers should find out what top management and non-HR managers expect from the HR department and then act upon it.

HR professionals add value when their efforts help people to achieve their goals. The HR value proposition, as suggested by Ulrich and Brockbank (2006), means that HR practices, departments and professionals produce positive outcomes for key stakeholders - namely, employees, line managers, customers and investors. Ulrich and Brockbank (2005, p. 18) elaborate on the concept of value by suggesting that the universal value premise is that value is defined by the receiver more than by the giver. This premise mandates that HR professionals begin with the end in mind by ensuring a line of sight to their key stakeholders. It requires that HR professionals focus less on what they do and more on what they deliver.' HR delivery is of great value to the relevant stakeholders. The HR manager should also be aware of tangible and intangible value.

The HR department needs to know what to measure in order to add value. De Bruyn and Roodt (2009) suggest that the HR department should be assessed through a quantitative audit to determine the strengths and weaknesses of the HR function. The real aim of HR management is to produce a scorecard that contains more knowledge-based metrics that report value or contribution-type information (Higgins, 2007). The purpose of the HR balanced scorecard is to manage organisational rather than individual performance. The various elements of the scorecard are included because they are understood to work together to achieve the desired performance outcome.

An effective approach in improving business performance is to measure the performance of financial and administrative functions against internal targets and benchmarks. A performance management system can be automated to provide information to management, making rapid action possible if changes are required. The goal of such an automated scorecard system is therefore to supply managers with information as quickly as possible so they can make effective changes. Phillips and Schmidt (2005) elaborate on this view by stating that organisational performance can be measured by means of a balanced scorecard.

HR competencies represent the characteristics, knowledge and skills of a HR professional. These competencies are necessary for successful performance. Becker et al. (2001, p. 156) define competence as 'an individual's knowledge, skills, abilities or personality characteristics that directly influence his or her job performance.' HR professionals have their own views on the necessary competencies they should possess. Examples of such competencies are: skills in communication, problem solving, leadership, recruiting and selection, an adherence to employment law, training and development, technology, forecasting, compensation design, benefits design and administration, and accounting or finance record-keeping. It is important for the HR professional to be a relationship builder an exceptional communicator, a conflict resolver, a creative HR leader one who assists line managers in pursuing the business strategy and one who increases an organisation's capacity for rapid change through addressing changed circumstances in business (Nel et al., 2006).

Becker et al. (2001) suggest five domains of competence - namely, personal credibility, management of change, management of culture, delivery of HR practices and knowledge of the business. An HR survey done by the Chartered Institute of Personnel Development (CIPD) (2003) revealed the most important HR competencies and capabilities. These include a willingness to innovate, integrity, negotiating skills, business knowledge, an ability to deliver targets, strategic thinking, leadership ability, empathy/communication/listening skills, understanding HR practices and influencing/political skills.

The International Public Management Association for Human Resources (IPMA-HR) (2009) emphasises that HR should have competencies in being a change agent, business partner, leader and HR expert. Some of the competencies for a chartered HR practitioner according to the South African Board for People Practices (SABPP) (2009) include integrating HR management and practices into an organisation's business strategy and operations, and co-ordinating and managing the core processes related to HR management and practices at an operational level in line with best practices.

Research conducted by the University of Michigan Business School also underscores this view of Ulrich and Brockbank (2006). The researchers determined that the success of the HR division is dependent on competency and specific skills in five key areas. Mondy and Noe (2005) mention these five key areas - namely, strategic contribution, business knowledge, personal credibility, HR delivery and HR technology.

In order to sustain a competitive advantage, the HR Department needs to master competitive intelligence $(\mathrm{CI})$. According to Kloppers (2005, p. 25), 'CI could act as a sensor to trigger and support decision-making by alerting a company to changes 
in the environment.' Brewster et al. (2008) give emphasis to the six elements that the HR professional should cover in gaining a competitive advantage. These elements are: being a talent manager and organisational designer, a culture and change steward, a strategy architect, an operational executor, a business ally and a credible activist. These authors also identify competencies for the HR professional, such as, knowledge about labour relations, HR strategy and performance management: traits such as integrity, conscientiousness and courage; as well as skills such as consulting skills, cognitive skills and collaborative skills. Nel et al. (2006) mention that the future integrative competencies for HR professionals are relationship builder, exceptional communicator, conflict resolver, creative HR leader, assisting line managers in pursuing the business strategy, and addressing changed circumstances in organisations. Finally, more recent research of Ulrich, Brockbank, Johnson, Sandholtz and Younger (2008) emphasises that the HR professional should be a credible activist, culture and change steward, talent manager/organisational designer, strategy architect, operational executor and business ally.

One of the main challenges facing mergers is HR-related issues. The HR division should therefore have essential HR competencies to drive the transformation process and to create value. The aim of this study was to determine these HR competencies in order to add value to a merged public, residential higher education institution in Gauteng.

The research questions addressed in this study were as follows:

- What are the HR competencies to add value to a merged higher education institution?

- How satisfied are the staff with these identified HR competencies of the HR Department at a merged higher education institution?

- What do the staff perceive the importance of these identified HR competencies at a merged higher education institution to be?

\section{RESEARCH DESIGN \\ Research design and method}

In order to achieve the aim of determining the HR competencies to add value to a merged higher education institution, a quantitative research design using a survey was employed.

\section{Population and sampling}

A convenience sample of 1363 permanent staff on one of the higher education institution's campuses was conducted. All the academic and administrative staff as well as the management at this campus were included. The staff and management from other campuses were excluded in this study. Due to the relocation of staff, only 1072 fulltime employees could be reached. Questionnaires and letters of consent were handdelivered to these 1072 employees. After two weeks, the researcher obtained 297 completed questionnaires from the various participating staff members. The response rate was $28 \%$.

\section{Ethical considerations}

The questions of the questionnaire were compiled in such a manner that it did not have any negative impact upon the higher education institution. The anonymity of the respondents was also respected. It is important to obtain the consent of the respondents to participate in a research project (Mouton, 2004). The respondents signed the informed consent forms that were handed out. The questionnaire, letter of consent and cover letter were approved by the institution's research and ethical committees.

\section{The measuring instrument}

An HR balanced scorecard was conducted at this institution as part of obtaining relevant information for the design of the questionnaire. An integration of the HR balanced scorecard, the literature review and the business plan led to the design of the questionnaire. The questions in the 5-Point Likert scale questionnaire (where $1=$ strongly agree, 2 = agree, $3=$ uncertain, $4=$ disagree and $5=$ strongly disagree) were derived from the integration of the necessary HR competencies. This information was obtained from the literature review, the business plan of the institution, as well as from the findings of the HR balanced scorecard. Two subscales were included namely, satisfaction and importance. Five themes were covered, with six questions in each theme. These questions were mixed and not posed under the headings. The reason for this was to avoid the leading of responses. Only closed-end questions were posed. Ten questionnaires were distributed among administrative and academic staff members as a pilot study to determine whether or not the questions were unambiguous and relevant. The Cronbach's alpha were utilised to measure the reliability of the questionnaire.

\section{Data analysis}

A principal factor analysis was utilised to reduce the large number of variables to a smaller number of factors for the purpose of identifying the HR competencies according to the staff of this institution. The factor loadings are the correlation coefficients between the variables (rows) and factors (columns). In the Statistical Package for the Social Sciences (SPSS), the factor loadings are found in a matrix labelled factor matrix when conducting a principal factor analysis. An oblique rotation was performed, and a pattern matrix and structure matrix were provided. The pattern matrix was used to investigate the factors for this study so only unique contributions of coefficients were identified.

Spider charts shed light on the satisfaction and importance factors. Box plots (also known as box-whisker diagrams) indicated the median, interquartile range, outliers and extreme cases of each factor. The graph was constructed in such a way that the distance between the lowest line and the edge of the shaded box indicates the lowest $25 \%$ of scores (bottom quartile). The shaded box indicated the distribution of the middle $50 \%$ of scores, while the top edge of the box up to the top part of the line indicates the top $25 \%$. The median was indicated by a line inside the shaded box. Outliers are unusual values with respect to the majority of the observations (Field, 2005). These outliers were indicated as separate points and identified by the case numbers.

\section{RESULTS}

In terms of gender, the sample is fairly evenly split between males and females, although there is a slight weighting towards female employees ( $58 \%$ female). Most respondents are between the ages of 30 and $49(66 \%)$, with $39 \%$ aged $30-39$ and another $27 \%$ aged 40-49. The majority of the respondents speak Afrikaans at home (63\%) with English being the second-most spoken language (14\%). Of the respondents, $23 \%$ have an African home

TABLE 1

Home language of the respondents $(n=295)$

\begin{tabular}{lll}
\hline & Frequency & \% \\
\hline Afrikaans & 187 & $63 \%$ \\
English & 41 & $14 \%$ \\
African & 69 & $23 \%$ \\
$\quad$ IsiNdebele & 3 & $1 \%$ \\
$\quad$ IsiXhosa & 5 & $2 \%$ \\
IsiZulu & 8 & $3 \%$ \\
$\quad$ Northern Sotho & 18 & $6 \%$ \\
Sesotho & 7 & $2 \%$ \\
Setswana & 13 & $4 \%$ \\
SiSwati & 2 & $1 \%$ \\
Tshivenda & 4 & $1 \%$ \\
$\quad$ Xitsonga & 5 & $2 \%$ \\
Other & 2 & $1 \%$ \\
\hline
\end{tabular}


TABLE 2

Designation of the respondents $(n=296)$

\begin{tabular}{lll}
\hline & Frequency & $\%$ \\
\hline Non-academic staff & 186 & $63 \%$ \\
Vice-chancellor & 1 & $0 \%$ \\
Deputy vice-chancellor & 3 & $1 \%$ \\
Registrar & 2 & $1 \%$ \\
Executive director & 1 & $0 \%$ \\
Chief director & 5 & $2 \%$ \\
Senior director & 3 & $1 \%$ \\
Director & 1 & $0 \%$ \\
Assistant director & 8 & $3 \%$ \\
Technical staff & 7 & $2 \%$ \\
Administrative staff & 134 & $45 \%$ \\
Information technology staff & 9 & $3 \%$ \\
Other & 12 & $4 \%$ \\
Academic & 110 & $37 \%$ \\
Dean & 1 & $0 \%$ \\
Head of academic department & 8 & $3 \%$ \\
Professor & 3 & $1 \%$ \\
Associate professor & 5 & $2 \%$ \\
Principal lecturer & 8 & $3 \%$ \\
Senior lecturer & 28 & $9 \%$ \\
Lecturer & 47 & $16 \%$ \\
Junior lecturer & 10 & $3 \%$ \\
\hline
\end{tabular}

TABLE 3

Number of years with the institution $(n=295)$

\begin{tabular}{lll}
\hline & Frequency & $\%$ \\
\hline Less than 5 years & 64 & $22 \%$ \\
$5-10$ years & 91 & $31 \%$ \\
$11-15$ years & 66 & $22 \%$ \\
More than 15 years & 74 & $25 \%$ \\
\hline
\end{tabular}

language of which Northern Sotho, the indigenous language, is the most prevalent $(6 \%)$.

The majority of the respondents are administrative staff $(45 \%)$, with a further $37 \%$ academic staff. Eight per cent of the respondents are at managerial level.

Most respondents have been working at this institution for at least five years $(78 \%)$. The single largest categories are for the 5 - to 10 -years group $(31 \%)$ and the 10 - to 15 -years group (22\%). Only $11 \%$ have been employed for longer than 20 years.

All individual items in these subscales contributed well to the overall reliability of the instrument. The reliability of the importance scales were as follows: the business knowledge and HR practice scale shows an extremely high reliability of 0.925 . Cronbach's alpha for the personal skills factor is satisfactory (larger than 0.70) with no single item not contributing to this factor, as illustrated by the item Cronbach's alphas which are all approximately 0.70 (if only reported to two decimal places). The reliability of the management skill factor overall is high (alpha $=0.838$ ), while all the individual items also contribute well to the overall reliability. The reliability of the satisfaction scales were as follows: the satisfaction with business knowledge and HR practices factor shows an extremely high reliability of 0.881 . All the individual items work well with this factor and it is therefore unnecessary to exclude any items in order to improve the reliability. The satisfaction factor for personal skills is somewhat lower than that of the same factor for importance $($ alpha $=0.730)$. By excluding the item on staff members trusting one another, the reliability will rise to above the 0.7 level, which is generally considered to be an adequate cut-off for reliable scales. This item is therefore excluded from further analyses and the factor consists of the remaining three items. The satisfaction factor for management skill is higher at 0.873 than

TABLE 4

Three-factor analysis results of the principal axis factor analysis

\begin{tabular}{|c|c|c|c|}
\hline & $\begin{array}{c}\text { FACTOR } \\
1\end{array}$ & $\begin{array}{c}\text { FACTOR } \\
2\end{array}$ & $\begin{array}{c}\text { FACTOR } \\
3\end{array}$ \\
\hline The HR department has adequate knowledge of HR practices & 0.764 & & \\
\hline I agree with the code of conduct as determined by the institution & 0.745 & -0.227 & \\
\hline The organisational structure of our department contributes to optimal performance & 0.727 & & \\
\hline I am well-informed about the services offered by the HR department & 0.71 & & \\
\hline The institution has fair labour practices & 0.704 & & \\
\hline The HR department takes accountability for its decisions & 0.698 & & \\
\hline The HR strategy is aligned to the institution's strategic plan & 0.686 & & \\
\hline The HR managers are able to provide competent staff & 0.681 & & \\
\hline The institution has a performance management system that rewards performance effectively & 0.608 & & \\
\hline The results of the recent staff satisfaction survey have been used to address challenging issues & 0.534 & & \\
\hline The HR department understands the workplace culture of the institution & 0.452 & & 0.234 \\
\hline The HR department communicates effectively on issues of change & 0.45 & & 0.2 \\
\hline I trust the managers of the HR department to manage staff effectively & 0.44 & & 0.229 \\
\hline The managers of the HR department understand the needs of staff & 0.362 & 0.337 & 0.229 \\
\hline HR manages to employ competent employees & 0.357 & 0.291 & \\
\hline The institution is a great institution to work for & 0.322 & & \\
\hline The HR department assisted effectively during the merger to make the change process work & & 0.564 & \\
\hline The managers of the HR department are effective leaders & & 0.506 & 0.241 \\
\hline Staff members trust each other & & 0.506 & \\
\hline I receive expert advice from the HR department about HR related matters & & 0.471 & \\
\hline Computer information systems help me to do my work effectively & & & 0.635 \\
\hline The HR department assists our department effectively in the financial management of our department & & & 0.619 \\
\hline The managers of the HR department value my opinion & & & 0.543 \\
\hline The managers of the HR department encourage staff to participate in the change processes & & 0.213 & 0.522 \\
\hline The managers cooperate with the training and development department to assist me effectively in developing my competencies & 0.305 & & 0.52 \\
\hline The HR department provides sufficient information for the management of our department & & & 0.509 \\
\hline The HR department acts proactively in bringing about change & & 0.404 & 0.41 \\
\hline Diversity is effectively managed at this institution & & 0.273 & 0.378 \\
\hline The HR department should contribute significantly towards a competitor analysis & 0.261 & & 0.313 \\
\hline I have a positive relationship with the staff of the HR department & 0.277 & & 0.304 \\
\hline
\end{tabular}


for the corresponding factor for the importance scale (alpha $=0.838$ ). Although the reliability should be slightly improved from 0.873 to 0.882 by excluding one item, this is not considered to be a sufficient improvement on an already high reliability to validate the exclusion of the item. All items are therefore included in the analysis.

A principal factor analysis was conducted and the items that loaded high on each of the three factors respectively were investigated for common themes.

The items that loaded high on each of the three factors, namely, business knowledge and HR practices (factor 1), personal skills (factor 2) and management skills (factor 3), respectively, were investigated for common themes. A comparison of the mean scores of the importance and satisfaction factors was done. These three factors formed the essential HR competencies needed to add value to the higher education institution.

Figure 1 indicates the average scores for the importance factors, while Figure 2 shows the view for the satisfaction factors.

Figure 3 shows the mean difference between scores on the satisfaction factors and the importance factors.

In order to understand the distribution of the factor scores in more detail, box plots are provided for the three importance and satisfaction factors. Figure 4 indicates the box plots for the importance scales and Figure 5 shows the box plots for the satisfaction scales.

\section{DISCUSSION}

The following HR competencies were identified, as a result of Table 4, to answer the research question with regard to the essential HR competencies to add value to a merged higher education institution:

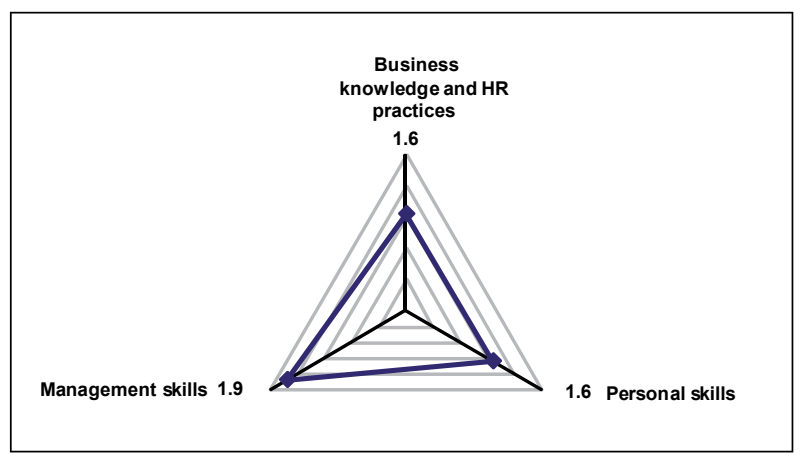

FIGURE 1

The mean scores on the importance factors

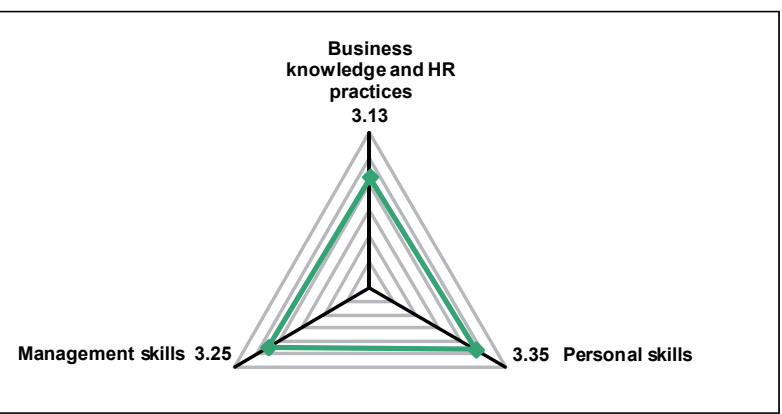

FIGURE 2

The mean scores on the satisfaction factors

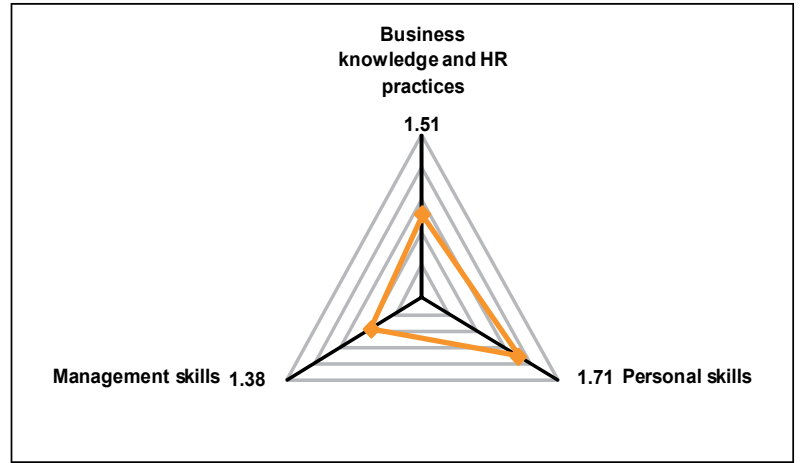

FIGURE 3

The mean difference between scores on the satisfaction factors and the importance factors

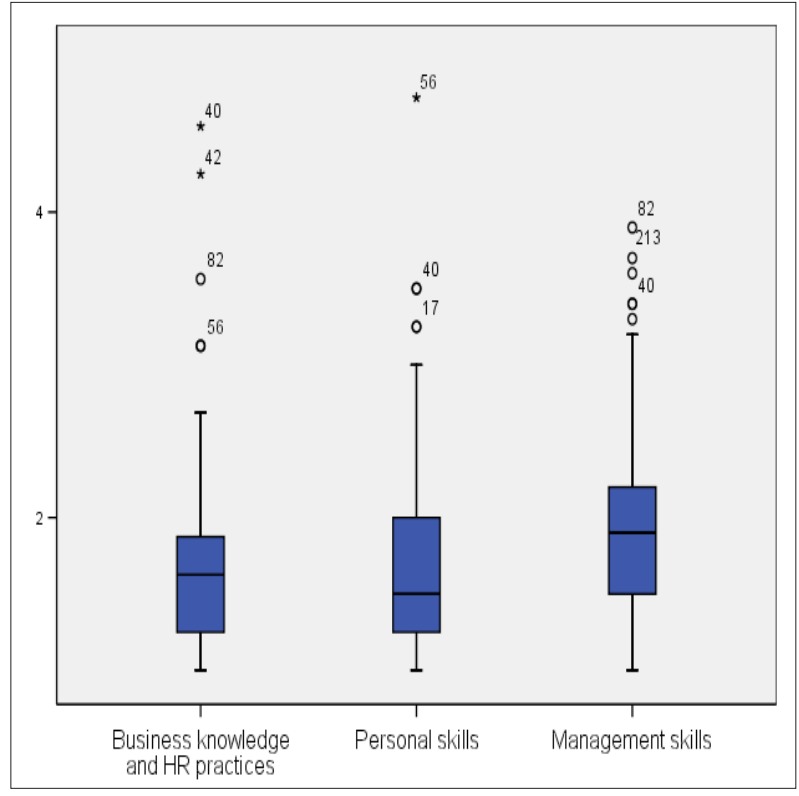

FIGURE 4

Box plots for the importance factors

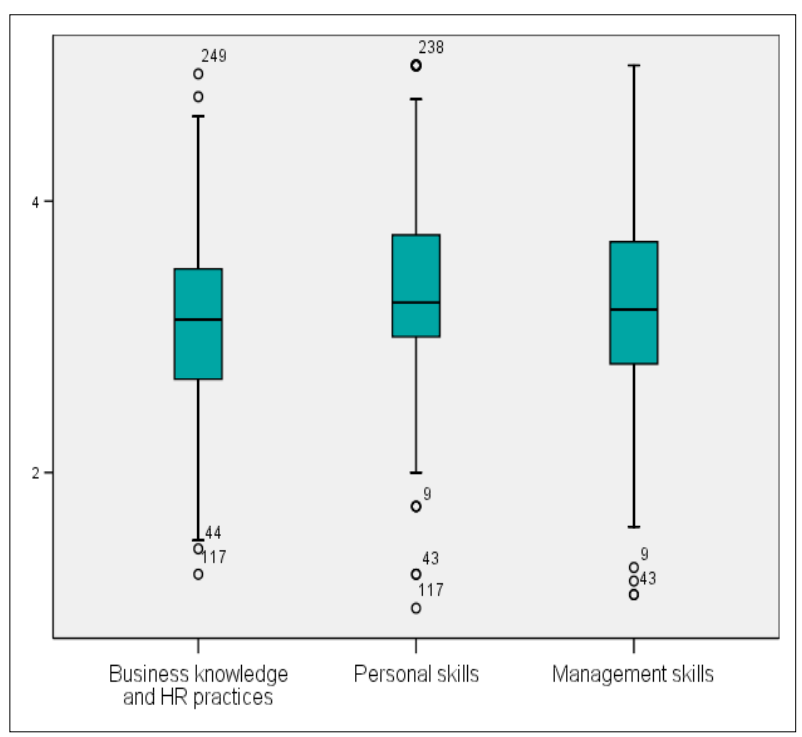

FIGURE 5

Box plots for the satisfaction factors 
Business knowledge and knowledge of HR practices: $H R$ managers and HR staff should have business knowledge such as competitive intelligence. Knowledge of external realities such as technology, economics, globalisation and demographics are of the essence. Furthermore, knowledge of HR practices, such as how to align the HR strategy with the business strategy contributes to the overall strategy by linking the internal organisation to external customer expectations, which are essential contributions to a merged institution. This aligns with the views of Ulrich and Brockbank (2005) and Storey (2007) about how the HR strategy and the business strategy must be integrated. Streamlined administrative processes, a sound performance management system, dual career paths for academic staff (teaching and research), attracting and retaining relevant expertise through interventions such as employment equity, succession planning and skills development opportunities, insightful management reporting and recommendations, and the development of leadership capability and process-automation are also essential. HR managers ought to compile a talent-management strategy with the purpose of enabling employees to be a source of sustainable competitive advantage to the institution. This concurs with De Bruyn and Roodt's (2009) findings. They $(2009$, p. 6) state that '... the right people with the right skills doing the right things will be attracted and retained'. HR managers should also be able to design the organisation by focusing on the capabilities the institution has that are embedded in structure, processes and policies that shape how an organisation works. Operational execution is therefore of essence in order to add value. Huselid Becker and Beatty (2005) accentuate the importance of worldclass HR practices and policies. Finally, HR managers and staff have to manage computer information systems as well as budgets effectively.

Personal skills: A professional image can be revealed through integrity. Rampersad (2003) presented much evidence of achieving performance with integrity. This concurs with the research of Van Aswegen and Engelbrecht (2009) with regard to ethical behaviour and integrity that instil confidence and trust. It is imperative to encourage respect, trust, credibility and a keeping of commitments. Accountability, accuracy, business ethics and inspiring others are essential competencies of the HR professional. This aligns with the views of Ulrich et al. (2008) of HR being a credible activist.

Management skills: Management skills will be discussed under the headings of managing change, managing culture and relationship management.

Managing change: Internal policies and management practices must be examined to accommodate change. Effective change agents guide the merged institution and keep its development process on track. The coordination of the different stages in the process and the constructive dialogue with all parties in the process are important. HR must have the ability to anticipate problems and implement solutions. Managing change also consists of the building relationships: keeping staff updated and rewarding them for their efforts are essential competencies. HR professionals should also be able to develop a change in management communication strategies to provide effective communication on change. Gibson, Ivancevich, Konopaske and Donnely (2006) are also of the opinion that open communication and the sharing of information will assist with the effective management of change. Ulrich et al. (2008) are in alignment with HR being a change and culture steward.

Managing culture: HR competencies with regard to managing culture are to recognise, articulate and help shape the institution'sculturebyclarifying externalcustomer expectations and translating these expectations into internal employee and organisational behaviours; improve organisational culture and morale by creating a caring, transparent environment conducive to managing change and diversity, and by building work relationships and internal partnerships through an environment that is conducive to open communication and trust. This is in agreement with Martins and Coetzee (2007) that respect and fair treatment and transparency are crucial to manage culture effectively. A diversity in the leadership team is required to do the following: guide the diversity initiative, implement a staff-satisfaction survey and establish communication channels to enhance effectiveness of internal communication and cooperation. Charlton (2002) accentuates that diversity leadership is about creating synergy from diversity. HR professionals must coach managers in how their actions reflect and drive the institutional culture.

Relationship management: High-level-performance teamwork, for example, through multidisciplinary and transdisciplinary teams and the establishment of service-level agreements between internal functions are of the essence. Becker et al. (2001) consider relationship management to be an integral part of HR. The improvement of relationship management can be done by means of positive internal relationships, open communication, staff motivation and culture, team development, and business allies. George and Jones (2007) believe that the development of a positive organisational culture and effective team development will enhance productivity. The HR professional's external relationships such as being a community 'partner' are of the essence.

The research questions concerning the views of staff regarding the importance and satisfaction of these HR competencies (resulting from Figures 1-5) will now be discussed. The scores for each of the factors were created by obtaining a mean score across all the items comprising a scale. In terms of importance, business knowledge, HR practices and personal skills are equally important (the mean score is 1.6) with management skills slightly less important with a mean score of 1.9 (a high score corresponds to low importance). The staff of the merging institution indicated that the HR Department should have adequate business knowledge to add value to this institution. In order to be an effective HR function, the HR Department should ensure that the different HR practices add value. The personal skills of the staff should be of such a nature that the staff can experience professionalism. Inspection of the box plots confirms that the average rating of the satisfaction factors is higher than that of the importance factors, indicating that respondents are less satisfied relative to the importance attached to all business knowledge and HR practices, as well as management skills. The greatest difference between satisfaction and importance is observed for the personal skills factor relative to its importance.

One would therefore conclude that the staff of this higher education merging institution are not entirely satisfied with the fact that the HR Department does not have sufficient business knowledge, that the HR practices are currently not satisfactory, and that there is a lack of personal skills and management skills in the HR Department. On the other hand, staff indicated that business knowledge, HR practices, personal skills and management skills are crucial to the HR Department adding value to this institution. An emphasis should be placed on assisting the staff of the HR Department to gain the necessary personal skills. In terms of satisfaction, however, all factor scores are similar with respondents being slightly more satisfied with business knowledge and HR skills (the average is 3.13 as opposed to 3.25 and 3.35 for management skills and personal skills respectively). Calculating the gap between the satisfaction and the importance of a factor makes it possible to interpret the relative performance of the factors. Overall, the respondents were less satisfied (i.e. high scores on the three factors relative to their adjudged importance). The greatest difference between satisfaction and importance is observed for the personal skills factor - relative to its importance, this factor performed the poorest. 


\section{Conclusion}

Change brings about many challenges for the HR professional and certain HR competencies are therefore needed to add value during these challenging times. Higher education institutions have a unique environment and the purpose of this study was to establish the HR competencies that could add value to merged institutions. This was done by conducting quantitative research. The questionnaire was derived from the literature review, the business plan and the HR balanced scorecard conducted at the institution. The principal factor analysis indicated that knowledge of business and HR practices, personal skills and management skills are the essential HR competencies in this environment. The process followed whereby knowledge was gained by means of recent literature on HR issues, including the business plan, conducting a HR balanced scorecard as well as an empirical study all contributed to a holistic view that determined the essential HR competencies for a merged higher education institution. The resolution is to focus on these HR competencies to add value to a merged institution. A value-driven HR department should have the essential HR competencies to enhance the level of success and competitive advantage.

\section{Recommendations and limitations}

HR departments could use these recommended HR competencies for effective management and facilitation during change and transformation. For conducting future research, it is recommended that an investigation should be conducted into the HR competencies of other higher education institutions in South Africa as well as abroad. This study could be extended by conducting research in the private and public sector of South Africa. The process of gaining knowledge through recent literature on HR management, the inclusion of the business plan, conducting a HR balanced scorecard as well as an empirical study could contribute to a holistic view of HR competencies needed in the South African milieu. It is recommended that other scorecards be used in the abovementioned process. The following scorecards are recommended: the workforce scorecard (Huselid et al., 2005), the total performance scorecard (Rampersad, 2003), the diversity scorecard (Hubbard, 2004) and the leadership scorecard (Phillips \& Schmidt, 2005). The number of respondents was limited due to the relocation of staff as a result of the merger. Another limitation is the fact that this study focused on one campus only. It must be kept in mind that this study was conducted at one higher education institution and that no further assumptions can be made with regard to the higher education system as a whole.

\section{Suggestions for future research}

In future research, this study could be extended by conducting research in other higher education institutions and other working environments for it is not known whether the HR competencies required may be different. The results of this study can be used as a starting point for developing a theoretical model that enhances the adding of value to HR departments. This model may also be used to measure the competence of the HR department. The application of the HR balanced scorecard and other scorecards in the higher education setting of South Africa may be researched to determine the relevance and significance thereof.

\section{REFERENCES}

Arnolds, C.A. (2005). An Alderfer perspective of the higher education restructuring in South Africa. South African Journal of Industrial Psychology, 31(2), 22-29.

Becker, B.E., Huselid, M.A., \& Ulrich, D. (2001). The HR scorecard: linking people, strategy and performance. Boston: Harvard Business School Press.

Birkin, M. (2005). Strategic HR scaling the peak. HR Future, April, 10-13.
Brewster, C., Carey, L., Grobler, P., Holland, P., \& Warnich, S. (2008). Contemporary issues in human resource management. Gaining a competitive advantage. (3rd edn.). Cape Town: Oxford.

Charlton, G. (2002). Human habits of highly effective organisations. Pretoria: Van Schaik.

Chartered Institute of Personnel and Development (CIPD). (2003). HR survey report. Retrieved November 26, 2009, from http://www.cipd.co.uk/subjects/hrpract/hrtrends / hrsurvey.htm

De Bruyn, L., \& Roodt, G. (2009). Applying the criteria of Ulrich and Brockbank for the assessment of the role of Human Resources as a strategic business partner in a mining company. South African Journal of Human Resource Management, 7(1), 1-11.

De Lange, N., \& Olivier, M.A.J. (2008). Nurturing human capital: A challenge for higher education institutions? South African Journal of Higher Education, 22(1), 41-61.

Dreher, G.F., \& Dougherty, T.W. (2001). Human resource strategy: A behavioural perspective for the general manager. Boston: McGraw-Hill.

Field, A. (2005). Discovering statistics using SPSS. Thousand Oaks, California: Sage.

George, J.M., \& Jones, G.R. (2007). Understanding and managing organizational behavior. (5th edn.). Englewood Cliffs, NJ: Pearson/Prentice-Hall.

Gibson, J.L., Ivancevich, J.M., Donnelly, J.H., \& Konopaske, R. (2006). (12th edn.). Organizations. Behavior, Structure, Processes. Boston: McGraw-Hill.

Hayes, J. (2008). Six sigma critical success factors. Retrieved January 29, 2008, from http://www.isixsigma.com/library/ content/c020415a.asp

Higgins, N. (2007). What gets measured gets done: Developing an HR scorecard. Retrieved January 30, 2008, from http://www. workinfo.com/Free/Downloads/164.htm

Hubbard, E.E. (2004). The diversity scorecard: Evaluating the impact of diversity on organizational performance. Amsterdam: Butterworth Heinemann.

Huselid, M.A., Becker, B.E., \& Beatty, R.W. (2005). The workforce scorecard: Managing human capital to execute strategy. Boston: Harvard Business School Press.

International Public Management Association for Human Resources (IPMA-HR). (2009). HR competencies. Retrieved November 26, 2009, from http://www.ipma-hr.org/content. $\mathrm{cfm}$

Kaplan, R.S., \& Norton, D.P. (2001). The strategic focused organization: How balanced scorecard companies thrive in the new business environment. Boston: Harvard Busines School Press.

Kilfoil, W.R., \& Groenewald, T. (2005). Mergers and change management at the micro level: A case study. South African Journal of Human Resource Management, 3, 1118.

Kloppers, C. (2005). Can competitive intelligence inform HR decision making? HR Future, July, 24-25.

Martin, A., \& Roodt, G. (2009). Perceptions of organisational commitment, job satisfaction and turnover intentions in a post-merger South African tertiary institution. South African Journal of Industrial Psychology, 34(1), 22-31.

Martins, N., \& Coetzee, M. (2007). Organisational culture, employee satisfaction, perceived leader emotional competency and personality type: An exploratory study in a South African engineering company. South African Journal of Human Resource Management, 5(2), 20-32.

Meisinger, S. (2003). Strategic HR means translating plans into action - from the president - human resource management. HR Magazine, March. Retrieved August 23, 2008, from http://findarticles.com/p/articles/mi_m3495/is_3_48/ ai_98830382

Mondy, R.W., \& Noe, R.M. (2005). Human resourcemanagement. (9th edn.). Englewood Cliffs, NJ: Prentice-Hall.

Mouton, J. (2004). How to succeed in your master's and doctoral studies. Pretoria: Van Schaik. 
Nel, P.S., Van Dyk, P.S., Haasbroek, G.D., Schultz, H.B., Sono, T., \& Werner, A. (2006). Human resources management. (6th edn.). Cape Town: Oxford University Press.

Phillips, J.J., \& Schmidt, L. (2005). Leadership scorecard. HR Magazine, July. Retrieved August 23, 2008, from http://findarticles.com/p/ articles/mi_m3495/is_7_50/ai_n14811640

Pillay, K., \& Wijnbeek, D. (2006). The corporate university training and learning solution for a South African airline industry. South African Journal of Human Resource Management, 4(2), 29-38.

Rampersad, H.K. (2003). Total performance scorecard: Redefining management to achieve performance with integrity. Amsterdam: Butterworth Heinemann.

Smith, H, \& Schurink, W. (2005). The interface between knowledge management and human resources: A qualitative study. South African Journal of Human Resource Management, 3(1), 6-13.

South African Board for People Practices (SABPP). (2009). Chartered HR Practitioner. Retrieved November 26, 2009, from http://www.sabpp.co.za/prof-registration-criteria/ 83. html

Storey, J. (2007). Human Resource Management: S critical text. (3rd edn.). London: Thomson.

Ulrich, D. (1997). Human resource champions: The next agenda for adding value and delivering results. Boston: Harvard Business School Press.

Ulrich, D. (1998). Delivering results: A new mandate for human resource professionals. Boston:Harvard Business School Press.
Ulrich, D. (2006). How human resources can add value. Management Today, 21(10), 28-30.

Ulrich, D., \& Brockbank, W. (2005). The HR value proposition. Boston: Harvard Business School Press.

Ulrich, D., \& Brockbank, W. (2006). Building sustainable value through your HR proposition. Conference proceedings of Global Leaders, 22 February 2006. Midrand, South Africa: Gallagher Estate.

Ulrich, D., \& Brockbank, W., Johnson, D., Sandholtz, K., \& Younger, J. (2008). HR competencies: Mastery at the intersection of people and business. Colorado: Society for Human Resource Management.

Van Aswegen, A.S., \& Engelbrecht, A.S. (2009). The relationship between transformational leadership, integrity and an ethical climate in organisations. South African Journal of Human Resource Management, 7(1), 1-9.

Van der Westhuizen, C., Van Vuuren, L.J., \& Visser, D. (2003). Human resource management as a profession in South Africa: practitioners' perspectives. South African Journal of Human Resource Management, 1(2), 1-12.

Van Vuuren, L.J., \& Eiselen, R.J. (2006). A role for HR in corporate ethics? South African practitioners' perspectives. South African Journal of Human Resource Management, 4(3), 22-28.

Zulu, P., \& Parumasur, S.B. (2009). Employee perceptions of the management of cultural diversity and workplace transformation. South African Journal of Industrial Psychology, $35(1), 1-9$. 